\title{
A common arrhythmia, not so common at an old age
}

\author{
A. A. M. Wilde
}

Published online: 11 January 2014

(C) The Author(s) 2014. This article is published with open access at Springerlink.com

An 80-year-old lady presents in your outpatient clinic with complaints of palpitations. There is no further cardiac history, her baseline ECG is normal (not shown) and so is her echo. A Holter monitor reveals the following registrations (Fig. 1a and b). What is your diagnosis?

a

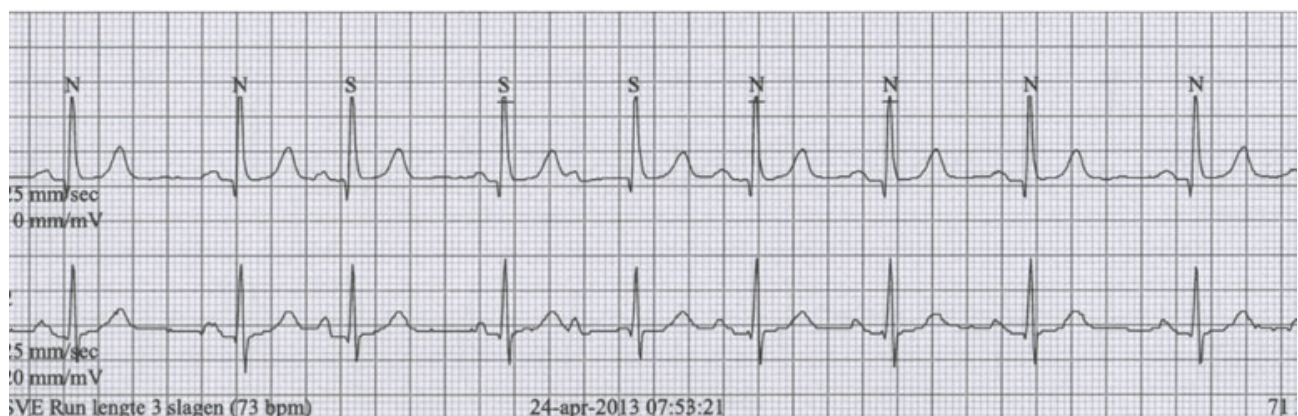

b

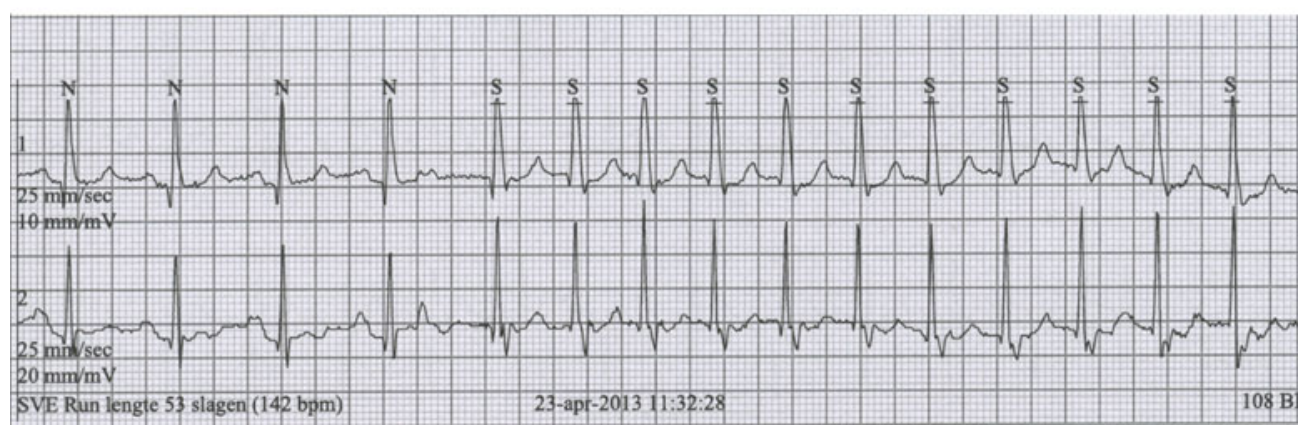

Fig. 1 ECG tracings from the Holter monitoring

A. A. M. Wilde $(\bowtie)$

Academic Medical Centre, Amsterdam, the Netherlands

e-mail: a.a.wilde@amc.uva.nl
Open Access This article is distributed under the terms of the Creative Commons Attribution License which permits any use, distribution, and reproduction in any medium, provided the original author(s) and the source are credited. 